Goldschmidt 2021 Abstract

https://doi.org/10.7185/gold2021.6597
Technology Projects of CNPC and CUPB(ZLZX2020-01-05), the Natural Science Foundation of China (No. 41702249).

\section{Carbon-oxygen isotope characteristics of alkaline lake dolomitic shale and its implications for reservoir sedimentation-diagenesis process}

\author{
LEILEI YANG ${ }^{1}$, WEIQUAN ZHAO ${ }^{1}$, ZHENXUE JIANG ${ }^{1}$, \\ LILIANG HUANG ${ }^{2}$, QIUSHENG CHANG $^{2}$, XIANGLU \\ TANG $^{1}$ AND ZHIYE GAO ${ }^{1}$ \\ ${ }^{1}$ China University of Petroleum, Beijing \\ ${ }^{2}$ Research Institute of Exploration and Development, Xinjiang \\ Oilfield Company of Petrochina \\ Presenting Author: yangleilei@cup.edu.cn
}

Stable carbon-oxygen isotope could well reflect the characteristics of ancient climate, sea level change and organic matter burial rate in geological history. It is an important geochemical index to analyze the sedimentary environment, diagenetic process and source rock development conditions. The Fengcheng Formation shale reservoir in Mahu Sag, Junggar Basin, China is a typical alkali-lake fine-grained mixed rock deposition, and the dolomitic shale is developed. However, the deposition-diagenesis process is not clear, which limits the exploration and development of resources. In this study, based on carbon-oxygen isotope and other petrological testing and analysis methods, combined with multiphase flow numerical simulation technology, aiming at the dolomitic shale of Fengcheng Formation in Mahu Sag, the characteristics of carbon-oxygen isotope are deeply discussed, and the sedimentation-diagenesis process are determined. Firstly, based on the carbon-oxygen isotope characteristics of lacustrine carbonate rocks, the ancient environment during deposition is judged by the projection point method and correlation coefficient, so as to reveal the difference between the water medium environment in the primary and diagenetic processes, and then to judge the salinity and openness of the lacustrine basin during the deposition process. Secondly, the oxygen isotope content in the measured rock samples is compared with the typical value of carbon-oxygen isotope to analyze whether the carbon-oxygen isotope value of the Fengcheng Formation reservoir shifted and further discuss the reasons. Then, the temperature of carbonate cement precipitation is analyzed, the formation time and conditions of carbonate cement and its influence on reservoir are determined and recovery of diagenetic evolution process. Finally, through the numerical simulation program of reservoir diagenesis, the diagenetic evolution process under different diagenetic conditions is simulated, and the formation conditions and time of carbonate cement are further determined to determine the diagenetic evolution process. By this study, the ancient environmental information and sedimentary environment of shale reservoirs can be determined, which is conducive to restoring the diagenetic evolution process and providing theoretical support for the development mechanism of shale reservoirs.

\section{Acknowledgments:}

This research is supported by the Strategic Cooperation 